\title{
América Latina y el Tercer Mundo*
}

\section{COAINTARIOS GENERALES}

Debemos reconocer que toda definición o diagnóstico es difícil en el momento actual. Se suele hablar de "fluidez" en las relaciones internacionales; lo anterior es especialmente relevante a partir del conflicto del Medio Oriente, de octubre de 1979. El Presidente Sadat, de Egipto, señalaba que los días de esa guerra habian cambiado el destino de la humanidad. Comparto ese criterio al recordar las insospechadas proyecciones de la crisis del petróleo, y de los procesos concomitantes que hemos vivido en los años 1974 y 75 , caracterizados por tendencias simultáneas de orden inflacionario y recesivo en los denominados "centros" de la economía internacional.

Me he definido como un "optimista profesional"; al presente no me he separado, sino que he acentuado tal enfoque. Porque cabe ser optimista al observar la reacción colectiva de los últimos meses, tanto de las naciones desarrolladas como de aquellas en rias de desarrollo, tendiente a definir nuevas normas o reglas del juego para la economía internacional, que hagan posible una coexistencia más racional entre naciones cuyos desniveles de crecimiento $y^{\perp}$ cuyas diferenciaciones estructurales se acentuan.

El concepto del "nuevg orclen económico internacional", que hubiera pareciclo hasta hace poco cono un "slogan", producto de quienes desean arreglar el mundo sin atender a su compleja realidad, se ha estado abriendo paso con gran fuerza descle la última reunión especial de las Naciones Unidas, en setiembre del año pasado. En el espíritu de dicho evento se han celebrado, en fecha reciente, reuniones entre paises industrializados y productores de materias primas, con vistas a establecer un diálogo Norte/Sur para crear condiciones más justas y estables en sus relaciones.

Es interesante constatar que estos encuentros han teniclo como fondo adversas condiciones políticas internacionales y dificultades inmediatas en el funcionamiento de las Naciones Unidas. Sin embargo, la necesidad de sobrevivenciat de la comunidad internacional fuerza a encontrar puntos de convergencia que superen negativas circunstan-

* Exposición del doctor Felipe Herrera en et Il Seminario Latinoamericano de Promoción de Exportaciones (Caracas, 20 de julio de 1976). 
cias que día a día se magnifican a través de los medios de información: En tal sentido tengamos presente los positivos pasos que se están dando en el proceso de la "reforma monetaria internacional '. Cierto es que las decisiones substantivas, y especialmente el acuercio de las naciones industrializadas, han tomado largos años en concretizarse creando un peligroso ambiente de incertidumbre mundial; pero no es menos cierto que en la actualidad, con las recientes resoluciones del FMI se está en el camino de aplicar un nuevo régimen, desligado de monedas determinadas y que reconoce la "desmonetización" del oro, metal que históricamente fuera la "viga maestra" de todos lós sistemas financieros. En ese contexto recordemos que en días recientes el FML ha procedido a la venta de una sexta parte clel oro en su poder y la devolución de una cantidad equivalente a sus países miembros. La parte sometida a venta $-24.000 \mathrm{~kg}$-- se destinará a la creación de un Fondo Fiduciario cuyo objetivo es dar asistencia a los países en vías de desarrollo con problemas en sus balances de pago.

En semanas recientes, UNCTAD ha clausurado su IV Conferencia General con resultados que, a mi entender, la diferencian positivamento de las reuniones de Ginebra (1964), Nueva Delhi (1968) y Santiago (1972). Digo positivamente porque no otra cosa es la unanimidad lograda, después de un largo e intenso forcejeo entre parte del mundo industrializado y! las naciones en vías de desarrollo para debatir la creación de un Fondo Común de 6.000 millones de dólares destinado a la formación de "stocks" reguladores de diez productos básicos esenciales.

Dicha resolución debe entenderse completada con las siguientes decisiones: a) la recomendación para que los países acreedores efectúen un estudio rápido favorable a una solución del angustioso problema de la bancarrota financiera de los 20 países más pobres del mundo, en función de las condiciones erosionantes para su economía, del endeudamiento externo; b) la adopción de un código de conducta para la transferencia tecnológica; y c) normas destinadas a regular las actividades de las empresas multinacionales.

Un aspecto destacado de la agenda en la reunión de Nairobi fue el tema "La Cooperación Económica entre los Países en Vías de Desarrollo". Hace algunos pocos meses tuve el honor de participar en un Grupo de Expertos cuyo objetivo fue precisamente preparar un documento que sirviera para una discusión más a fondo del asunto, documento que fue considerado, primero, por la reunión preliminar de los " 77 ", en Manila, y luego en el recientc foro de UNCTAD ${ }^{1}$.

3 "La Cooperación Económica entre los paises en desarrollo". Informe del Grutpo de Expertos, Ginebra, 27 de octubre a 4 de noviembre de 1975 (Documento UNCTAD, TD/B/AC. $19 / 1 ; 17$ de dicicmbre de 1975). 
En los trabajos señalados es de gran interés constatar lo que las circunstancias prevalecientes del Tercer Mundo en su conjunto hacian prever: América Latina ha tenido una experiencia especial, en todos los planos de su desarrollo colectivo, lo que permite aportar valiosas contribuciones que pueden servir precisamente para reforzar la "autoafirmación" que se busca de los países en vías de desarrollo. En ese orden de cosas, nos correspondió en la Presidencia del Bạco Interamericano, a principio de la décadá del 60, una participación activa para la creación de un Banco Africano dej Desarrollo; luego, para la estructuración del Banco Asiático y, más adelante otorgạ la asesoría técnica para la formación del Banco de Desarrollo. del Caribe. Las iniciativas mencionadas fueron tal vez los primeros indicios de una cooperación técnica que superara el convencional vęrticalismo Norte/Sur, para transformarlo en una dimensión horizontal Sur/Sur.

Evidentemente que el BID representa la creación institucional de mayores perspectivas en el campo de la cooperación financiera $Y$; técnica de países pertenecientes a un mismo sistema regional. La creación del Banco no fue fácil, ni política ni técnicamente. El ambiente distinto observable en los últimos diez años para la creación de entidades regionales o subregionales, expresa precisamente los mayores problemas que enfrentan las naciones subdesarrolladas, en su mayor gravitación y autonomía política, y la posibilidad de utilizar modelos ajustables a sus necesidades.

No pretendemos sostener que todas las experiencias latinoamericanas sean automáticamente aplicables a otras regiones del mundo, ya que como es sabido, las diversidades entre los ț propios países err vía de desarrollo son cada vez mayores. En la actualidad se está hablando de un "Cuarto" y aún de un "Quinto Mundo" para poder captar a mayor cabalidad las diferenciaciones regionales y nacionales.

Pareciera ya una platitud recordar que el $70 \%$ de la población del mundo, con sólo un 30\% de sui renta global, está muy lejos de cons. tituir un bloque monolítico. Ese grupo de naciones utiliza con persistencia la definición acuñada por De Gaulle - Tercer Mundo- definiendo, en los días de auge de la bipolarización y de la guerra fría, que dicha parte de la humanidad aspiraba a un camino propio en el enfrentamiento entre los EE.UU. y el mundo capitalista industrializado, por una parte, y la Unión Soviética y los países socialistas de la Europa Oriental, por la otra. En tal sentido y aun cuando no existe una completa superposición, la noción de Tercer Mundo tiene raices comunes con el movimiento de los denominados "países no alineados".

Es evidente que la transformación de OPEP en un poderoso y determinante instrumento de la política económica internacional, a 
partir de 1979, tiende a crear en el Tercer Mundo una línea divisoria entre los países exportadores de petróleo y aquellos que no cuentan con estos excedentes. Subrayo, "tiende a crear", porque a pesar del énfásis de algunos políticos y medios de publicidad de los países industrializados de acentuar las diferencias entre paises en desarrollo exportadores de aquellos importadores de petróleo, en la práctica, las naciones cuyos recursos esenciales son las materias primas han mantenido un fuerte grado de cohesión, como lo revelan los eventos internacionales de diversa naturaleza a los que hemos hecho referencia,

En diversas partes del globo, los países medianos y pequeños en vias de desarrollo buscan esquemas de' integración regional y subregional, modalidades que tienden a superar su falta de riabilidad económica y politica. En ese contexto es también cada vez más observable que en variados foros internacionales se tiende a una representación conjunta por grupos de países con afinidades geo-económicas, evitándose así la dispersión de opiniones, y las dificultades propias de negociaciones internacionales con un número excesivo de participantes.

Creemos que los esquemas integracionistas tenderán, cada vez más, no sólo a ser mecanismos de entendimiento "interno" entre países asociados, sino que también instrumentos para una colaboración entre 'diversos grupos regionales. Presenciaremos así un inevitable progreso de los que pudiéramos denominar un escenario "integracional" de entendimiento y cooperación. Recordemos que en la actualidad un $50 \%$ de los países en vías de desarrollo forman parte de esquemas de integración regional o subregional.

\section{LA COOPERACIÓN ENTRE LOS PAÍSES DEL TERCER MIUNDO}

Las relaciones económicas tradicionales han tenido una orientación geográfica que pudiera definirse de Norte a Sur, es decir, entre naciones desarrolladas con aquellas en vias de desarrollo. En los últimos 20 años un nuevo escenario lo constituye la relación Este/Oeste, para definir los vínculos económicos entre los países del mundo occidental, con aquellos de organización socialista. Prosiguiendo con el enfoque geográfico podemos denominar como cooperación Sur/Sur aquella que se produce entre los paises del Tercer Mundo. Estas formas de vinculaciones también se denominan de "cooperación horizontal". Por cierto que el enfoque geográfico para determinar las relacio- 
nes entre paises puede ser cuestionado, ya que no expresa en su integridad la actual realidad global del mundo contemporáneo; sin embargo, debemos aceptarlo por via de "nomenclatura".

Más allá de estas definiciones lo que interesa es el reconocimiento de un hecho y de una aspiración histórica nueva, a saber, que la denominada parte "șumergida de la humanidad" está principiando a conocerse, a dialogar, a buscar soluciones y frentes comunes. La tradicional relación "vertical" con las antiguas metrópolis y con los nuevos centros del poder económico y político del siglo $\mathrm{XX}$, tiende a ser completada por los escenarios "horizontales".

Se trata de un proceso nuevo, que empieza a esbozarse timidamente en los primeros años de la Segunda Post-Guerra, para emerger con imprevista vitalidad en los últimos dos lustros. Como ya lo hemos señalado, pasos importantes en esta dirección son los esquemas hacia la integración regional y subregional que no sólo se hacen tangibles en nuestra América Latina, sino que también en el Africa Oriental y Occidental, en el mundo árabe, $y^{\prime}$ a través de inicitivas sectoriales, entre los países asiáticos. El alineamiento de países productores de petróleo y de determinados rubros básicos, también es un factor decisivo para estra nueva e irreversible situación internacional, de la que todos nosotros hemos sido testigos presenciales, $\dot{y}$ a veces también, protagonistas.

La nueva situación se reconoce por las Naciones Unidas en términos enfáticos y prioritarios al considerar como uno de los pilares del Nuevo Orden Económico Internacional la denominada "autoafirmación colectiva" de los países en vías de desarrollo. En el Programa de Acción adoptado por.la VI Sesión Especial de, la Asamblea de las Naciones Unidas, se declara que los países del Tercer Mundo deben "promover la autoafirmación colectiva entre ellos y fortalecer. una cooperación internacional de interés recíproco con miras a estimular su desarrollo acelerado".

Las nuevas condiciones de la realidad económico-política contemporánea son favorables al objetivo señalado, particularmente por la mayor capacidad negociadora de una parte importante del Tercer Mundo en función del control de combustibles y materias primas esenciales para el crecimiento de la economía internacional.

Tratándose de una nueva realidad, aún se está lejos de. contar con mecanismos, sistemas o regímenes adecuados que faciliten esta cooperación en los campos esenciales del comercio, de los transportes, del financiamiento, y de la ciencia y de la tecnología. En los párrafos que siguen trataremos de sistematizar algunas de las formas que ese trabajo en común puede revestir. 


\section{0.- Cooperación Financiera}

No eran desconocidas, con anterioridad a octubre de 1973 , diversas formas de iniciativas de cooperación financiera entre países en vías de desarrollo. El sistema de los Bancos regionales, al constituirse sobre la base de colaboraciones más importantes de los países más avanzados de un grupo en vías de desarrollo y las preferencias al financiamiento de naciones medianas o pequeñas, constituyen una expresión de este enfoque. Los vínculos cada vez más estrechos entre los Ban$\cos$ Centrales de estos países, que en innúmeras oportunidades actúan en operaciones de apoyo a las balanzas de pago y a la promoción del comercio entre naciones que por razones geográficas $y / o$ políticas tienen especial vínculo, también es una expresión de lo señalado.

En nuestro propio continente ha sido muy frecuente que las naciones latinoamericanas mayores (México, Venezuela, Brasil y Argentina) hayan otorgado facilidades crediticias, e incluso han efectuado donaciones a países vecinos o bien de menor desarrollo dentro del área. En el mismo coñtexto recordemos la cooperación especiai que algunos de estos países han otorgado a instituciones subregionales, como el Banco Centroamericano de Integración Económica (BCIE) y la Corporación Andina de Fomento (CAF). Señalemos. también las políticas del Banco Interamericano de Desarrollo (BID) de vender bonos a los Bancos Centrales de aquellas naciones de América Latina que en momentos determinados han contado con reservas excedentes.

Sin embargo, ha sido sólo en los dos últimos años y medio, por la activa participación de OPEP, que se puede testimoniar la existencia de importantes programas de cooperación financiera entre países en vías de desarrollo. Esta cooperación ha tenido diversas expresiones, que por su carácter nuevo y original, no permite aún una sistematización definitiva para su clescripción estadística e institucional ?.

Los países de la OPEP muestran con legitimo orgullo la forma de cómo han utilizado una parte importante de los superavits en sus balanzas de pagos para cooperar con otros paises del Tercer Mundo, sea por la vía bilateral o multilateral, en forma de créditos convencionales o bien concesionarios. Entre 1973 y 1974, los compromisos totales aumentan en más de cinco veces, hasta llegar a una cifra cercana a los 15.000 millones de dólares. Para el primer semestre de 1975

2 Los datos que utilizamos en los siguientes párrafos provicnen de informaciones de la Secretaría de la OECD y de la UNCTAD. 
hay compromisos financieros por más de $S$ mil millones de dólares. Tanto en 1974 y 1975 dichas operaciones se dividen en partes más o menos iguales entre aquellas que se otorgan bajo condiciones concesionales (blandas) y aquéllas de carácter convencional (de acuerdo con las condiciones de los mercados financieros).

En relación a la situación de los desembolsos, que por su naturaleza propia son sustancialmenta inferiores a las sumas comprometidas, es interesante expresar las sumas correspondientes en porcentajes del PNB de los miembros de la OPEP: en 1973, alcanzan al 1,1\%; en 1974 aI 1,9\%. Comparados estos porcentajes con aquellos de los paises miembros de la OECD, cuyo flujo neto en esos mismos años oscila en torno al $0,38 \%$, es evidente que la contribución relativa de los países productores de petróleo comparada con la de los industrializados es varias veces mayor ${ }^{3}$.

En el informe del Grupo de Expertos que se reuniera' en Ginebra a fines del año pasado, se deja testimonio que "los paises de la OPEP han superado con mucho la ayuda concedida por los países desarrollados, en relación. con sus respectivos productos nacionales brutos. Esas corrientes se han dirigido, sin embargo, hacia un número relativamente reducido de beneficiarios $y$ no se han orientado en una medida que pueda considerarse satisfactoria hacia el grupo de los países más gravemente afectados. El aumento sin, precedentes de los déficit de las balanzas de pago de los países en desarrollo importadores de petróleo a partir de 1973 , no ha sido cubierto más que en parte por las donaciones y las inversiones directas de los países en desarrollo con superávit. Otra corriente ha pasado a través del servicio financiero del petróleo del FMI, en gran parte financiado por los países de Ia OPEP. Otra parte considerable, aunque no determinada, del déficit ha sido cubierta por las corrientes indirectas que pasan por los mercados financieros del mundo desarrollado, corrientes, la mayoría de las cuales son, sin embargo, a corto plazo y por consiguiente, de carảcter volátil. De hecho estas corrientes están agravando la carga de la deuda de los países en desarrollo, sobre todo de los más gravemente afectados".

\section{$20 \rightarrow$ Coopreración Comercial}

No nos debe extrañar qua las corrientes comerciales entre los países del Tercer Mundo sólo constituyan un porcentaje minimo de su vomen total de intercambio. En efecto, entre 1971 y 72 el valor del

3 Deben recordarse las tesis de UNCTAD para proveer a una transferencia minima neta entre el $0,7 \%$ y el $1 \%$ del PNB de los paises avanzados. 
comercio entre países en vías de desarrollo sólo representaba un quinto de sus exportaciones totales. Es significativo comparar estas cifras con el comercio reciproco entre países desarrollados, de economía de mercado, para los cuales corresponde al $75 \%$ de sus exportaciones totales. Entre los paises socialistas de la Europa Oriental, dicha proporción es de un $60 \%$. Si tomamos como indicador el PNB (excluyéndose a los países exportadores de petróleo), el comercio entre los países del Tercer Mundo es 'sólo equivalente a un $2 \%$ de su producto, en relación a un $9 \%$ entre las naciones desarrolladas.

Las corrientes comerciales latinoamericanas con las naciones en vías de desarrollo son una expresión de lo que venimos planteando. Para el Oriente Medio y el Asia (excluido Japón) exportábamos entre 1960-1963, un 0,8\% del total. Diez años más tarde, entre 19701973, esa cifra llega al 1,9\%. El comercio de importación para dichas regiones representan entre 1960.63 , un $3 \%$, y para $1970-73$, un $3,7 \%{ }^{*}$

Las circunstancias que influyen, en las modestas cifras anteriores son fáciles de explicar: los países en vias de desarrollo, han dependido y siguen dependiendo grandemente en sus relaciones comerciales de los centros industriales más avanzados. Lo anterior se acentúa si se considera el sistema de mercadeo y distribución, de fletes marítimos, de seguros, y de facilidades crediticias orientados entre los países "centro" y aquellos de la "periferia". No han existido, obviamente, facilidades análogas entre países en vías de desarrollo. Si consideramos por vía de ejemplo, en una visión. histórica, lo precario de las relaciones comerciales intralatinoamericanas, sexá fácil visualizar la debilidad del intercambio del Tercer Mundo en su conjunto.

En consecuencia, las acciones destinadas a promover corrientes de intercambio directas entre naciones en vías de desarrollo tendrán que basarse en acciones concertadas y permanentes de carácter bilateral o multilateraI. Naturalmente que las modalidades que estas nuevas corrientes de comercio pueden tomar, dependerá de los sistemas económicos' prevalecientes en estos países; en consecuencia, la búsqueda de fórmulas de promoción para el intercambio de losi países en vías de desarrollo tendrá que sujetarse a un gran pragmatismo, donde tanto los gobiernos como los respectivos sectores privados tienen importantes funciones que desempeñar. Como se ha recordado, América Latina está en estos últimos años, progresivamente, aprendiendo a conocer la realidad comercial de algunos paises del Africa, del mundo árabe y del Lejano Oriente. Se puede observar el incremento promisorio de contactos exploratorios que se han estado concretando,

4 Banco Interamericano de Desarrollo, Progreso Socioeconómico de América Latina, 1974 (p. 77$\rangle$. 
especialmente para los paises mayores de América Latina, en contratos de ventas de bienes y servicios.

El sistema de Preferencias Generales, en forma de ventajas no reciprocadas de los países industrializados para aquellos en vias de desarrollo, ha sido aceptado ampliamente, después de un Iargo y dificultoso diálogo, comenzado con motivo de la primera reunión de UNCTIAD en 1964. Sin embargo, sóla hasta fecha reciente se ha planteado la conveniencia de establecer un régimen de preferencias generales entre países en vias de desarrollo. Obviamente dicho comercio preferencial ya ha existido entre naciones ligadas por acuerdos de integración regional o subregional; de lo que se trata ahora es extender esta concepción a todo el escenario del Tercer Mundo.

En tal sentido se pronuncia el informe de los Expertos, ya mencionado en otras oportunidades, cuando literalmente expresa:

"Los acuerdos preferenciales constituyen un importante instrumento para facilitar el comercio entre los paises en desarrollo. Para que sean plenamente efectivos, es preciso, sin embargo, que las preferencias estén integradas en un sistema general de cooperación económica entre dichos países. Las preferencias comerciales pueden constituir un valioso complemento 'de los instrumentos activos de promoción directamente encaminados a la transformación de las estructuras tradicionales de producción, transporte, banca y comercio".

\section{9 - Cooperación Monetaria}

América latina ha tenido una interesante experiencia, tanto en el Mercado Común Centroamericano como entre los países de ALALC, respecto a la aplicación de mecanismos de compensación como tégimen de pagos, como asimismo en la concesión de créditos recíprocos entre Bancos Centrales.

En la medida en que otras regiones en vias de desarrollo concierten acuerdos de carácter análogo, puede incluso proyectarse un régimen de pagos entre los paises del Tercer Mundo que ligue entre sí a los referidos sistemas. Como es sabido, mecanismos de pago de esta naturaleza, completados con facilidades financieras a corto plazo, constituyen útiles instrumentos para la promoción de los intercambios de bienes y servicios en todas sus formas.

Otra expresión de cooperación monetaria entre los países del Tercer Mundo puede visualizarse en función de una acción concertada de sus Bancos Centrales, ya sea nacionalmente o en grupos regionales, mediando la utilización coordinada de una parte de las reser- 
vas monetarias internacionales, dando así al Tercer Mundo una presencia más efectiva en el cuadro financiero internacional.

En otras oportunidades, y recientemente con motivo del I'Seminario de Promoción de Exportaciones Latinoamericanas, celebrado en Porto Alegre (Brasil), he planteado la utilidad de un sistema de Banca Central para América Latina, basado en una utilización conjunta de parte de nuestras reservas monetarias, en una coordinación permanente de las politicas monetarias y en mecanismos de cooperación entre nuestros países frente a situaciones de desequilibrios en sus balances de pagos generados por factores intrarregionales. El mecanismo en referencia podria actuar como la base institucional para un mecanismo de compensación multilateral de pagos que abarcara a los países de ALALC, del Mercado Común Centroamericano y de la Asociación de Librd Comercio del Caribe (CARIFTA).

\section{$49-$ Empresas Multinacionales}

En los últimos años se ha definido una tendencia hacia la formación de empresas que abarquen recursos de dos o más paises en vías de desarrollo, y cuyo objetivo sea la satisfacción de sus: necesidadesi de producción y de servicios.

Uno de los objetivos básicos del Sistema Económico Latinoamericano (SELA) es precisamente estimular esta forma de cooperación entre nuestros paîses, promoviendo una útil y pragmática integración sectorial. En el cuadro latinoamericano cabe destacar que el inicio de acciones conjuntas sectoriales de contenido multinacional resultaron del apoyo y promoción del Banco Interamericano de Desarrollo, en el curso de la década de los 60 , orientada principalmente hacia el campo de la infraestructura física (carreteras, puertos, desarrollos hidroeléctricos, telecomunicaciones, etc.). Las instituciones financieras subregionales, vale decir, el Banco Centroamericano de Integración Económica y la Corporación Andina de Fomento, de acuerdo con las normas institucionales y operativas que las rigen, han orientado parte importante de sus esfuerzos hacia estas finalidades.

Podemos entender por empresas multinacionales del Tercer Mundo aquellas que emanan de "un acuerdo formal y duradero concertado entre dos o más países en vias de desarrollo, o entre nacionales de esos países, con el propósito de alcanzar un objetivo común en las esferas de la producción, el comercio o la prestación de servicios. El elemento unificador de las empresas multinacionales es la existencia de un objetivo económico común a dos o más países o agrupa- 
ciones del Tercer Mundo, para cuya realización se requiere una acción conjunta en la que se comparten los recursos"naturales, la tecnología, las actividades de gestión, la responsabilidad financiera, la propiedad de los bienes y los mercados. ${ }^{5}$

De la definición anterior se desprende que, tal como para otra clase de vinculaciones entre los países en vía de desarrollo, debe enfatizarse un criterio de carácter pragmático en relación a la participación de los gobicrnos y de los sectores privados. La fisonomía juríclica - pública, mixta o privada- dependerá de la naturaleza de los intereses que se movilicen en función de cstas empresas. Pero tan importante como la estructura institucional de las nuevas empresas son sus aspectos de financiamiento, de gestión, de tecnología, etc.

Múltiples son los objetivos concretos que pueden tener las empresas en referencias. Por vía de ejemplo mencionemos la utilización de recursos que difícilmente podrían explotarse en funcióni de un solo mercado nacional; la integración cle distintas fases en un proceso de producción, aprovechando el carácter complementario de los diversos recursos y mercados de los paises que participan en la empresa; la organización de circuitos de producción orientados a obtener economías de escala considerando especializaciones en una misma rama de la inclustria y asignando para los diversos socios distintas líneas de producción el clesarrollo conjunto de zonas fronterizas; la construcción. y utilización de obras de infraestructura; el transporte marítimo y' aéreo; las actividades bancarias y financieras de cliversa indole; el sistema de seguros; el asesoramiento y consultoría destinado a mejoras en la capacidad gerencial y en la absorción tecnológica; etc.

Mención especial debe hacerse a las perspectivas multinacionales de empresas vinculadas con el comercio internacional, por las ventajas que su establecimiento podría significar para fines del mercadeo, cle la información y cle la promoción, y en general, para un aprovechamiento más efectivo de una capacidad de negociación que un grupo de países pucliera tener en función de mecanismos de esta naturaleza. Lo anterior es particularmente váliclo en el campo de la importación para países meclianos o pequeños que forman parte de agrupaciones regionales. Una acción colectiva en este sector puede significar el mejoramiento notorio en materia de precios y créditos, en la calidad y otras concliciones cle las compras, así como también en la reducción de los gastos de transporte marítimo y seguros como consecuencia de importaciones de mayor volumen.

5 Informe cilado, p. 15 . 


\section{$5^{\circ}-$ Cooperación Técnica}

La prestación de servicios técnicos entre países en vias de desarrollo es ya una modalidad en pleno funcionamiento. Hay diversos gobiernos entre los paises mayores del Tercer Mundo que han proseguido en periodos recientes politicas de asistencia técnica para naciones de menor desarrollo relativo, considerando no sólo especiales vínculos regionales, sino que también especiales ligazones políticas y comerciales. Muchas veces estas iniciativas han constituido los primeros pasos para apertura de mercados y para crear vínculos económicos permanentes de diversa naturaleza.

La labor de muchas organizaciones internacionales al servir de vehículo para la utilización de expertos del Tercer Mundo, por parte de naciones subdesarrolladas que tradicionalmente recurrían para estos fines al mundo industrializado, ha tenido también gran trascendencia.

El Programa de las Naciones Unidas para el Desarrollo (PNUD), le ha dado alta prioridad a esta modalidad de la cooperación internacional, para cuyo propósito se tha programado una Conferencia Mundial, en Buenos Aires, para el próximo año. Dicho evento está siendo precedido por encuentros regionales, uno de los cuales tuvo lugar en Lima, en el mes de mayo pasado.

Es lógico que la cooperación técnica entre países del Tercer Mundo se vincula estrechamente con los procesos de la transferencia tecnológica. Es ya lugar común repetir que las naciones subdesarrolladas requieran módulos tecnológicos propios, que no sólo se dapten a las necesidades de su crecimiento económico, en términos equilibrados, sino que también preserven sus valores culturales.

En el vasto escenario del Tercer Mundo las experiencias técnicas comparativas entre regiones o países son de la más grande importancia. Es indispensable crear y fortalecer los canales que permitan aprovechar reciprocamente las experiencias originales de países con problemas análogos. Esta forma de cooperación horizontal permitiría palear la "dependencia tecnológica", que muchas reces tiende a crear' serios desajustes que se manifiestan en un desarrollo que no es capaz de gestar oportunidades de empleo más generosas para las poblaciones rápidamente crecientes de los países en vias de desarrollo.

Diversas son las formas en que la cooperación técnica en referencia puede expresarse. Mencionemos sólo la programación en grupos regionales a subregionales de programas de asistencia técnica en beneficio de los países más atrasados; la organización por los países en 
desarrollo, con capacidades técnicas especiales, de proyectos especificos de cooperación técnica con otras naciones del Tercer Mundo; la colaboración entre los países en vías de desarrollo de la investigación conjunta, especialmente mediante el establecimiento o la utjlización de instituciones comunes o cooperativas que faciliten el jntercambio de informaciones técnicas y cientificas y la formación profesional; etc.

\author{
PERSPYCTYYAS LATYNOAMERICANAS
}

Como en todo proceso social, para ưna más adecuada visualización de una situación contemporánea es indispensable no perder de vista sus antecedentes previos y factores condicionantes. La década de los 60 y su continuación en los años inmediatamente siguiertes marca, desde diversos ángulos, el principio de un nuevo período para América Latina. Se han repetido las cifras y las estadísticas que definen esos años, particularmente hacia el final de los mismos, como un periodo global de expansión y de prosperidad. La gravitación del comercio exterior - con relaciones de intercambios positivas y negativas- se proyecta en este período. En estos años existe, además, un nuevo impulso motor, caracterizado principalmente en. los paises mayores por un crecimiento interno que se asienta fundamentalmente en un vitalizado proceso de industrialización. Las nuevas políticas de cooperación interamericanas, particularmente la presencia promotora del $\mathrm{BID}$, en su doble connotación financiera y técnica, contribuye también a la nueva dimensión.

A mi entender, es el proceso de la integración económica latinoamericana el hecho más relevante de estos años. No es una coincidencia que los esquemas básicos, regionales y subregionales, de alcance económico, comercial y financiero se gesten en este períddo. Como ya se ha señalado, también esta etapa, la banca central profundiza sus vinculos en el ámbito continental y coadyuva mediante mecanismos multilaterales a sistemas de pagos destinados a hacer funcionar el Mercado Común Centroamericano y la Asociación Latinoamericana de Libre Comercio.

Es frecuente testimoniar el escepticismo en tomo a la integración económica de América Latina. Se mencionan las dificultades de ALALC, los conocidos problemas politicos del istmo centroamericano y las limitaciones que pareciera sufrir el Grupo Andino. Dichas voces, sin embargo, no consideran los siguientes factores: a) Que las 
relaciones interlatinoamericanas de carácter comercial, financiero y técnico han teniclo en estos últimos I5 años una desconocida expansión. Recordemos hasta que punto nos ignorábamos unos a otros hasta ese entonces y de cómo nuestras relaciones eran casi exclusivamente bilaterales, principalmente entre paises vecinos; b) Que América Latina, desde principios dé los 70 se ve enfrentada a diversos problemas globales en la escala internacional. Mencionemos sólo los más recientes: la nueva situación de las materias primas y de la energía, y la crisis del sistema monetario intemacional y de la ayuda cxtema. Es interesante constatar como nuestros países, a pesar de las diferencias de sus regímenes políticos y sociales que parecieran acentuarse en los últimos años, asumen, sin embargo, en su frente económico externo, importantes posiciones comunes. Pareciera que el proceso de integración que empezamos a recorrer, a partir de 1960 , como un medio para superar entre nosotros los obstáculos del subdesarrollo, hubiera tomado un nuevo "escenario", en el cual América Latina, frente a otros grandes centros de poder o bloques de países, trata de acentuar y defender un destino común.

La afirmación anterior la vemos expresada con persistencia en las actitudes latinoamericanas solidarias frente a los probelmas del medio ambiente, de la población, de los alimentos y del habitat, según se expresa en las importantes conferencias internacionales de Estocolmo de 1972, de Bucarest en 1974, de Roma de 1975 y de Vancouver el presente año.

Una expresión de lo que estamos planteando fue también. la VII Reunión Especial de la Asamblea General de Naciones Unidas, donde surgen las expresiones de un "nuevo diálogo" entre el mundo industrializado y las naciones en vias de desarrollo.

La posición solidaria de América Latina en UNCTAD IV completa positivamente esta enumeración. Las antiguas aspiraciones latinoamericanas, que durante la década de los 50 se plantearon a través de CEPAL y posteriormente -en Ios 60- en UNCTAD, se transforman en la actualidad en términos de referencia del nuevo "orden económico internacional". En esa realidad el escenario del Tercer Mundo al cual América Latina se incorpora permite la vigencia de una nueva perspectiva. Hemos señalado que la clécada pasada testimonia el principio del encuentro económico-técnico de nuestros pueblos. Es también a partir de la segunda mitad de los 60 cuando los vínculos de solidaridad histórico-politica con los países en clesarrollo, empieza a definirse. Hoy América Latina es parte esencial de esos $2 / 3$ de la humanidad. Sin América Latina el Tercer Mundo no se hubiera transformado en un nuevo "centro cle poder" internacional; por otra parte, sin su activa participación y solidaridad con las 
otras regiones de esc escenario, nuestro continente no tendria el grado de gravitación internacional que al presente parece presentársele.

Es evidente que las aristas que crea esta perspectiva toman fuerza en función de la "globalización" de la época contemporánea, que ha determinado la emergencia - por vez primera en la historia del hombre- de una "civiliđación planetaria".

Al final de la década pasada me correspondió participar en reuniones, de diversa naturaleza donde se discutía el decenio de los 70 en función clel fuluro de nuestro continente. En uno de dichos eventos expresé lo siguiente:

"Hay quienes opinan que la asociación de nuestros paises con Ios del resto del Tercer Mundo no tiene sentido, teniendo en cuenta las escasas relaciones de cualquier tipo, que aparentemente mantenemos con Africa o con. Asia, en circunstancias en que estamos mucho más vinculados con algunos paises avanzados. Fste juicio es parcialmente verdadero, ya que si bien debemos reconocer que en determinados períodos hemos mantenido vínculos culturales y politicos más estrechos con estos últimos paises, los problemas de exportación de nuestro petróleo, azúcar, cobre, hierro, estaño, café son básicamente los mismos que tienen los productores de materias primas cle las regiones señaladas. Asimismo, las crecientes dificultades para obtener financiamiento, para absorber los avances de la ciencia y de la tecnología $y$, en fin, para alcanzar: tasas más altas de clesarrollo, son esencialmente de la misma naturaleza que las que enfrenta el resto de los países en vias de desarrollo".

América Latina está llamada a dar una decisiva contribución al "mundo planetario" de hoy. El actual problema económico contemporáneo es más un asunto de "oferta" que de "demanda". Nuestros economistas y nuestras politicas públicas se han orientado tradicionalmente en controlar a plazos cortos o medianos los flujos monetarios $y$ fiscales, y aquellos elementos subyacentes que pudieran crear un desequilibrio coyuntural en la economía. Desgraciadlamente en muchas oportunidades hemos propuesto las preocupaciones po: mejorar las condiciones de una producción minera, agrícola y energética que a plazos medianos y más largos pudiera dar una respuesta a los problemas de la escasez de recursos que enfrenta el munclo contemporáneo. Hoy en día, más y más, frente a la rápicla expansión demográfica $y$ el aumento creciente de sus consumos, se visualiza la necesidad de contar con los rubros fundamentales que la naturaleza nos puede entregar, y que han estado sufriendo una crisis de escasez. América Latina es una de las pocas regiones de amplios recursos naturales aún no utilizados, en un contexto internacional 
donde la transferencia tecnológica puede y debe hacerse cada vez más fluida.

Conocidas son las crecientes tasas de crecimiento de algunas de nuestras naciones, especialmente en aquellas donde existe una interesante masa crítica, es decir, una conjunción de recursos en el plano natural, humano, financiero, institucional y tecnológico. Es un hecho que en la América Latina contemporánea se estám formando grandes polos de desarrollo. Felizmente que dichos centros han revelado tanto en su concepción de la estrategia de las relaciones interlatinoamericanas, un criterio de apoyo y cooperación. hacia los países medianos y. pequeños.

A veces estas formas de cooperación interlatinoamericanas han sido mal interpretadas, lo que es atribuible a la nueva realidad del continente. Recordemos como entre los países que se asociaron al Plan Marshall se consideró esencial que aquellos que hubieran avanzado más rápidamente en el camino de su reconstrucción tenían una obligación política, y aún moral, de cooperar con aquellas naciones y regiones de Europa que, por diversas circunstancias, hubieran estado atrasadas en su crecimiento. Un ejemplo de lo anterior es la política europea frente al sur de Italia, política a la que se da un contenido de carảcter comunitario y multinacional.

En el último período, el "latinoamericanismo" ha tomado una nueva perspectiva. La tesis de los Presidentes de Venezuela y México parat crear un mecanismo de cooperación entre nuestros países, se han logrado concretar, en un interesante proceso tle consenso en torno a la creación del Sistema Económico Latinoamericano (SELA). Las recientes reuniones de Panamá y Caracas, con participación de todos los paises en vías de desarrollo del hemisferio, han, servido para definir lo que será este nuevo instrumento y para fijarle una estructura orgánica adecuada. A través de SELA se propende a tener institucionalizado un sistema permanente de cooperación regional en, sus múltiples aspeclios y a crear un mecanismo permanente de promoción para los objetivos de integración económica, que en último término deberá traducirse en alguna fórmula parecida a la Comunidad Económica Europea. Es decir, SELA deberá cumplir el rol de "conciencia" integracionista de América Latina. En ese contexto es auspicioso recordar que en semanas pasadas (mayo de 1976) el Convenio Constitutivo de SELA, negociado y firmado en Panamá, en noviembre de 1975 , por los 25 países en vías de desamollo dẹ hemisferio, fuera objeto de ratificación por mayoría absoluta, lo que permite institucionalmente el funcionamiento pleno del nuevo Sistema.

El foro de SELA servirá para generar iniciativas de carácter mul- 
tinacional; ya no sólo se trata de proyectos que digan. relación con inversiones vinculadas a obras de infraestructura que comprendan a dos o más paises, sino que también a empresas que actúen en sectores prioritarios determinados en el ámbito latinoamericano: las denominadas "multilatinas".

SELA facilitará la labor de definir políticas económicas externas comunes para nuestro Continente sea en el palno internacional $o$ interamericano, o bien frente a espećficicas realidades sectoriales. Una de las preocupaciones centrales de SELA será el orientar iniciativas que tiendan a evitar y a corregir los desajustes que se han ido acentuando entre nuestros países por disímiles tasas de crecimiento. El futuro de una América Latina unida, donde se hubieren erradicado frustraciones de antiguo cuño nacionalista, radica precisamente en una mayor homogeneidad, de sus partes constitutivas.

En líneas anteriores hemos enfatizado la importancia de la convergencia de los países del área en torno a tareas concretas, como una nueva perspectiva que debe completar el enfoque más bien global de la integración de la década pasada. Entre los diversos desafíos cuya respuesta debe estar en este criterio de convergencia quiero enfatizar las tendencias hacia la creación de una verdadera "comunidad académica latinoamericana", expresión del nivel de maduración intelectual al que está llegando el Continente en los campos de la cultura, de la ciencia y de la tecnología. Es un hecho reconocido de cómo ha mejorado el nivel de preparación de nuestros economistas, y en general de los cultores de las ciencias sociales. El Programa de "Estudios Conjuntos para la Integración Económica Latinoamericana" (ECIEL) es una tangible demostración de esta afirmación. Es de interés observar cómo a través de ECIEL más de 30 Institutos de Economía Iatinoamericanos, con una dotación de muchos centenares de investigadores, se asocian a la tarea de emprender investigaciones que, basándose en las realidades nacionales, persiguen una interpretación del conjunto regional.

Se ha definido a ECIEL como una "Cooperativa Académica Interlatinoamericana" por sus caracteristicas de tratar de aunar a un nivel colectivo, de carácter comparativo, los resultados analíticos efectuados en la escala nacional, sujetándose lo anterior a metodologías comunes. EI Programa cuenta ya cor más de 10 años de existencia; recientemente su. Centro de Coordinación se ha transferido a Rio de Janeiro, con miras a su latinoamericanización final. Importantes han sido los estudios comunes emprendidos en torno a la industrialización latinoamericana, a las estructuras y niveles de eficiencia productiva, a los sistemas salariales y de precios comparativos en campos diversos, al problema del empleo y de la absorción de la mano 
de obra, a los niveles de consumo y' de distribución de ingresos, $y^{\prime}$ más recientemente, a la investigación de la interacción entre educación y desarrollo económico.

UN BANCO LATINOAMERICANO PARA EL TERCER MUNDO

Al establecerse Ias bases para la creación de SELA los países latinoamericanos consideran como uno los objetivos generales de esta organización "promover un sistema permanente de consulta y coordinación para la adopción de posiciones y estrategias comunes sobre temas económicos $y$ sociales, tanto en los organismos y foros internacionales como ante terceros países y agrupaciones de paises". ${ }^{6}$

Esta función de SELA cobra especial relcvancia para la creación $y$ desarrollo de vínculos con otras regiones del mundo en desarrollo. Asi se reconoce en la reunión del Consejo Latinoamericano -órgano directivo.superior de la organización-cuando en su primera reunión extraordinaria (Caracas, enero de 1976) señala entre los lineamientos futuros de SELA desarrollar "contactos y proposiciones conjuntas para intensificar la vinculación y cooperación. con los países en desarollo de Africa y Asia; fundamentalmente en lo concerniente a materias primas, expansión del comercio y cooperación en obras de infraestructura".

De acuerdo con la filosofía $c$ inspiración de SELA sus actividades no interfieren en la acción de cada uno de sus integrantes. En relación al tema que nos interesa - de cómo est'ablecer vínculos pragmíticos entre los países latinoamericanos y otras regiones en desarrollo del mundo- hay un amplio margen para las iniciativas nacionales de toda indole, de naturaleza gubernamental o bien privada.

Sin embargo, a nuestro entender, la estructura de SELA debería ser el vehiculo para la creación de un órgano técnico-bancario cuya finalidad esencial sería la cooperación de nuestras naciones con el Tercer Mundo, según se explica sumariamente en los párrafos siguientes.

Tengamos presentle que el financiamiento de las exportaciones de bienes de capital y de manufacturas en general, fuera del área latinoamericana, no cuenta con mecanismos adecuados. Tampoco existe un mecanismo de financiamiento y promoción cuando se trata de facilitar la exportación de bienes y servicios que provengan de emprendimientos que abarquen a dos o más paises de la región.

- Art. 39, letra b), del Convenio de Panamá. 
En el contexto del financiamiento de las exportaciones de equipos, y de productos manufacturados, es efectivo que hay algunos países que están atendiendo en forma cada vez más efectiva estas necesidades; sin embargo, y particularmente para las empresas típicamente nacionales no existe, en la mayoria de nuestros paises, estas modalidades de asistencia. Salvo excepciones, tampoco existen regimenes adecuados de seguros a reaseguros para los créditos que pudieran conceder nuestros exportadores. $Y$ en general, a pesar de ciertos progresos efectuados en los últimos años, pudiéramos considerar como inadecuadas las políticas destinadas a facilitar nuestro comercio exterior y nuestros vínculos técnicos directos con los demás países del Tercer Mundo.

Por las circunstancias anteriores nos permitimos sugerir que SELA, de acuerdo con su sistema de trabajo, proceda a crear un Comité de Acción cuyo propósito sea estudiar la factibilidad de establecer un Banco Latinoamericano para el Tercer Mundo.

Esta entidad debería operar básicamente en el campo del financiamiento y del seguro a las exportaciones, sea directamente o a uraves de organismos financieros ya existentes. Tendría las características fundamentales de los Eximbank de algunos paises desarrollados. Además, debería ser un mecanismo de cooperación técnica, de información y de promoción. Tengamos presente la importancia que tuviera el Eximbank de los EE. UU., a partir de la década de los 30, en la política económica externa de clicho país, y antes que se crearan las actuales instituciones multilaterales y bilaterales de cooperación económica $y$ financiera.

Creemos que un Banco de Comercio Exterior de esta naturaleza no necesita de un capital de gran volumen, ya que visualizamos que una parte sustantiva de sus recursos puede ser formada con fondos provenientes de los mercados financieros latinoamericanos e internacionales.

La existencia al presente de poderosas instituciones bancarias latinoamericanas, sea de propiedad pública, privada o mixta, serviria de valioso apoyo para la formación de una firme infraestructura institucional y técnica para el mecanismo que se propone. ${ }^{7}$

La creación de dicho Banco multilateral podría tener un profundo impacto promocional para las potenciales corrientes latinoamericanas de venta de bienes y servicios en otras regiones en desarrollo. Salvo casos de excepción, por calificadas circunstancias nacionales e insti-

7 Los países de las Conmunidades Europeas, a pesar de contar con órganos nacionales de reconocida solvencia y experiencia, están en vias de crear un Banco Europeo de Exportaciones, existiendo una recomendación en tal sentido, de $1 a$ Comisión al Consejo de las Comunidades. 
tucionales, pareciera difícil para gran parte de nuestros paises abrirse fácil camino en mercados desconocidos y con la presencia tradicional de naciones avanzadas que obviamente nos aventajan en sus condiciones competitivas. Recordemos también los problemas de fletes en función de mercados reducidos y/o de cargas limitadas. No parece ilusorio pensar que por la vía de la agregación multinacional latinoàmericana, muchos de estos "cuellos de botella" pueden ser superados.

La institución que se propone debería abrir agencias en diversas ciudades claves de Africa y Asia, actuando con definido criterio comercial, financiero y técniço que la aleje de procedimientos burocráticos.

Hacia el futuro no debe descartarse la posibilidad que América Latina, en términos multilaterales pueda dar cooperación financiera y técnica a regiones o paises de notorio subdesarrollo de otras partes del Tercer Mundo; el Banco que proponemos debe ser el instrumento para estos objetivos, como en general para la amplia gama de formas de cooperación económica que la futura evolución del Tercer Mundo, sin lugar a dudas, irá requiriendo de América Latina, en función de la afirmación de nuestra presencia en el campo inte nacional. 